\title{
AVALIAÇÃO DA MORFOLOGIA DA SUPERFÍCIE DE PEÇAS EM TERPOLÍMERO ABS E EM PVC APÓS CONDICIONAMENTO QUÍMICO
}

\author{
A. P. KUREK ${ }^{1}$, M. E. R. DOTTO ${ }^{1}$, P. H. H. ARAÚJO ${ }^{1}$, N. SELLIN $^{2}$ \\ ${ }^{1}$ Universidade Federal de Santa Catarina, Departamento de Engenharia Química e Engenharia de \\ Alimentos \\ ${ }^{2}$ Universidade da Região de Joinville, Mestrado em Engenharia de Processos \\ E-mail para contato: anapkurek@gmail.com
}

RESUMO - O terpolímero ABS (acrilonitrila-butadieno-estireno) é o polímero mais empregado na fabricação de peças cromadas com função decorativa. No entanto, apresenta maior custo de processamento quando comparado a termoplásticos commodities, como o poli(cloreto de vinila) (PVC). Visando à substituição do ABS, neste trabalho, peças em PVC foram submetidas ao prétratamento em solução sulfocrômica sob diferentes condições de concentração, tempo e temperatura e em seguida foram cromadas. A modificação na superfície das peças foi analisada por microscopia eletrônica de varredura (MEV), microscopia de força atômica (AFM) e rugosidade. A qualidade da deposição metálica foi avaliada por inspeção visual e teste de aderência. Amostras em PVC foram menos susceptíveis ao condicionamento químico do que as em ABS. A adesão da camada metálica e alterações significativas na morfologia e rugosidade foram observadas somente em amostras de PVC tratadas em condições mais severas.

\section{INTRODUÇÃO}

A galvanoplastia é definida como um processo pelo qual uma determinada superfície é recoberta por metais, com o intuito de torná-la mais resistente à corrosão ou melhorar o seu aspecto estético. No processo de cromagem em polímeros, para uma adequada adesão desta camada, a superfície do polímero precisa ser modificada por processos químicos e/ou físicos (KUREK, 2009). A modificação superficial consiste usualmente na criação de cavidades, nas quais a camada metálica irá se fixar. O terpolímero ABS (acrilonitrila-butadieno-estireno) é o polímero mais empregado na fabricação de peças cromadas com função decorativa. No entanto, rápidas mudanças vêm exigindo das empresas maior competitividade, em busca de produtos com qualidade e menor custo (BOS, 2012). Uma alternativa é a substituição do ABS pelo policloreto de vinila (PVC), pois dentre os polímeros, o PVC é um dos mais versáteis (NUNES, 2006). No pré-tratamento de peças em $\mathrm{ABS}$, o condicionador de uso habitual é composto por $400 \mathrm{~g} / \mathrm{L}$ de ácido crômico e $400 \mathrm{~g} / \mathrm{L}$ de ácido sulfúrico, tempo de reação de 10 a 15 minutos e temperaturas de 60 a $65^{\circ} \mathrm{C}$ (TEIXEIRA, 2005). Esta solução apresenta resultados ótimos de adesão e ainda é a mais barata e mais usada pelas galvânicas. No entanto, da mesma forma que para o ABS, a superfície de peças em PVC deve sofrer modificações que favoreçam a adesão das camadas 
metálicas depositadas na cromagem. Portanto, este trabalho tem como objetivo estudar o efeito do processo de modificação superficial de peças de PVC na metalização deste material.

\section{MATERIAIS E MÉTODOS}

\subsection{Preparação do composto de PVC}

O composto de PVC foi preparado em um misturador da marca Intensivo Mecanoplast ML-9, conforme formulação descrita na Tab. 1.

Tabela 1: Formulação do Composto de PVC.

\begin{tabular}{ccc}
\hline Matéria-prima & Função & Concentração (\%) \\
\hline Norvic SP 700 RA & Resina de PVC K57 & 83,8 \\
Maftosa FE CZ 5023 & Estabilizante Térmico Ca/ZN & 4 \\
Paraloid K1120 ND & Modificador de Fluxo & 1 \\
Paraloid KM 334 & Modificador de Impacto & 6 \\
CaCO 3 Precipitado & Carga Orgânica & 5 \\
Acido Esteárico & Lubrificante Externo & 0,2 \\
\hline
\end{tabular}

O composto foi alimentado em uma extrusora, marca Miotto, com $30 \mathrm{~mm}$ de diâmetro de rosca. A resina de PVC foi produzida e transformada em pellets, no centro de Tecnologia e Inovação (CTI) na linha de extrusão Busano - MD 52, da Empresa Braskem (Brasil), e transformada em peças pelo processo de injeção da Empresa Durin Ltda. (Brasil).

\subsection{Modificação da superfície de PVC}

As peças de PVC foram submetidas ao pré-tratamento em diferentes concentrações da solução sulfocrômica sob agitação constante, em diferentes temperaturas $\left(50,60\right.$ e $\left.70{ }^{\circ} \mathrm{C}\right)$ e tempos de imersão $(5,10$ e $15 \mathrm{~min})$. Todos os testes foram realizados em duplicata. Após o condicionamento, as amostras foram enxaguadas vigorosamente em água corrente e submetidas às etapas convencionais empregadas no processo industrial de galvanização para a deposição da camada metálica (neutralização, ativação, aceleração, deposição química de níquel, deposição eletrolítica de cobre, níquel e cromo). A cromagem das amostras foi realizada na empresa Sigmacrom Indústria e Comércio de Artefatos Plásticos Ltda. (Brasil).

\subsection{Caracterização por inspeção visual e testes de adesão após processo de cromagem}

Inspeção visual: analisou-se a presença de defeitos, como deposição incompleta do metal e peças danificadas, segundo ABNT NBR 10283 (2008).

Testes de adesão: as peças foram fixadas em um dispositivo e serradas manualmente, evitando descascamento nas superfícies de corte (norma interna DBL 8465, 2002). 


\subsection{Avaliação das modificações na superfície das amostras}

Para a avaliação por MEV, AFM e rugosidade foram selecionadas as amostras imersas na solução condicionante sulfocrômica com concentração de $350 \mathrm{~g} / \mathrm{L}$ de ácido crômico e $400 \mathrm{~g} / \mathrm{L}$ de ácido sulfúrico, com tempos de imersão de 5 e 15 minutos e a $70{ }^{\circ} \mathrm{C}$.

Microscopia eletrônica de varredura (MEV): as amostras foram cortadas em pedaços pequenos, metalizadas com ouro para tornarem-se eletricamente condutoras e então analisadas em microscópio eletrônico de varredura (JEOL JSM-6390LV) com filamento de tungstênio, voltagem de aceleração de $15 \mathrm{kV}$ e ampliação de 3000 vezes, do Laboratório Central de Microscopia Eletrônica (LCME) da UFSC.

Microscopia de força atômica (AFM) e rugosidade: as amostras foram posicionadas no equipamento modelo Nanosurf Flex AFM, do Laboratório de Sistemas Anisotrópicos Departamento de Física - CFM/UFSC, operando em modo intermitente (Tapping Mode), ponta modelo TAP 190, com raio menor que $10 \mathrm{~nm}$, frequência de ressonância de $190 \mathrm{kHz}$, constante de mola de $48 \mathrm{~N} / \mathrm{m}$ e velocidade de varredura de 1 linha/s. As imagens obtidas foram tratadas usando o programa WSxM e a partir deste foram gerados os perfis de rugosidade.

\section{RESULTADOS E DISCUSSÃO}

A modificação da superfície das peças em PVC puro submetidas à solução condicionante foi avaliada pela qualidade do acabamento cromado. Na Fig. 1 estão apresentados defeitos que foram a base de discussão dos resultados apresentados adiante.
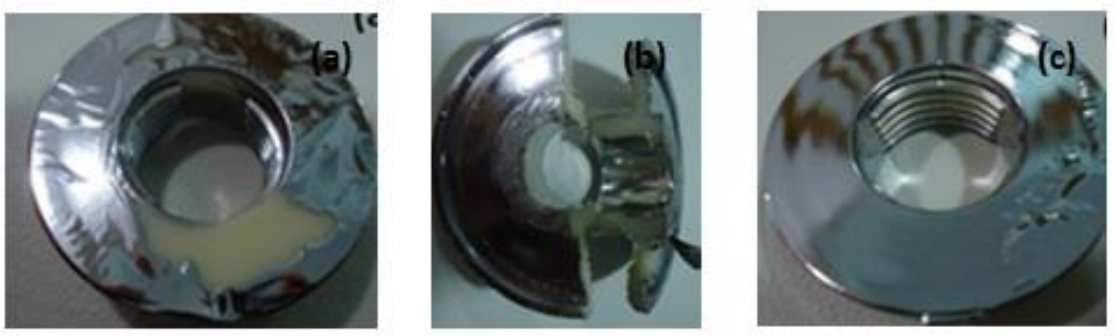

Figura 1: Fotos das amostras após a metalização indicando presença de defeitos: (a) deposição incompleta da camada metálica, (b) desplacamento no teste de corte com serra e (c) embolhamento no teste de ciclo térmico.

Observa-se pela Fig. 1 (a), (b) e (c) defeitos ocasionados pelo mau condicionamento, como a remoção de parte da camada metálica da superfície da peça, mostrando que a mesma não possui interação com a superfície do polímero. Foi usada como referência amostras em ABS, testadas nas mesmas condições.

Os resultados da avaliação do teste de adesão realizados nas amostras de ABS puro e no PVC puro com soluções contendo diferentes concentrações de ácido crômico no banho condicionador, sob diferentes tempos de imersão e temperaturas, estão apresentados na Tabela 2. 
Tabela 2: Avaliação da qualidade da deposição metálica nas amostras de ABS puro e PVC puro condicionadas em soluções de ácido sulfúrico e ácido crômico.

\begin{tabular}{|c|c|c|c|c|}
\hline \multirow[b]{2}{*}{ Solução } & \multirow[b]{2}{*}{ Tempo (min) } & \multirow[b]{2}{*}{ Temperatura $\left({ }^{\circ} \mathrm{C}\right)$} & \multicolumn{2}{|c|}{ Adesão } \\
\hline & & & $A B S$ & $P V C$ \\
\hline \multirow{9}{*}{$\begin{array}{c}\text { Ácido Crômico } \\
300 \text { g/L Ácido } \\
\text { Sulfúrico } 400 \\
\text { g/L }\end{array}$} & 5 & 70 & A & NR \\
\hline & 10 & 70 & A & NR \\
\hline & 15 & 70 & NR & NR \\
\hline & 5 & 60 & A & NR \\
\hline & 10 & 60 & $\mathrm{~A}$ & NR \\
\hline & 15 & 60 & A & NR \\
\hline & 5 & 50 & NR & NR \\
\hline & 10 & 50 & A & NR \\
\hline & 15 & 50 & $\mathrm{~A}$ & NR \\
\hline \multirow{9}{*}{$\begin{array}{c}\text { Ácido Crômico } \\
350 \text { g/L Ácido } \\
\text { Sulfúrico } 400 \\
\text { g/L }\end{array}$} & 5 & 70 & A & NR \\
\hline & 10 & 70 & $\mathrm{~A}$ & NR \\
\hline & 15 & 70 & NR & A \\
\hline & 5 & 60 & A & NR \\
\hline & 10 & 60 & A & NR \\
\hline & 15 & 60 & A & NR \\
\hline & 5 & 50 & NR & NR \\
\hline & 10 & 50 & $\mathrm{~A}$ & NR \\
\hline & 15 & 50 & A & NR \\
\hline \multirow{9}{*}{$\begin{array}{c}\text { Ácido Crômico } \\
400 \text { g/L Ácido } \\
\text { Sulfúrico } 400 \\
\text { g/L }\end{array}$} & 5 & 70 & A & NR \\
\hline & 10 & 70 & A & NR \\
\hline & 15 & 70 & NR & A \\
\hline & 5 & 60 & A & NR \\
\hline & 10 & 60 & $\mathrm{~A}$ & NR \\
\hline & 15 & 60 & $\mathrm{~A}$ & NR \\
\hline & 5 & 50 & NR & NR \\
\hline & 10 & 50 & A & NR \\
\hline & 15 & 50 & $\mathrm{~A}$ & $\mathrm{R}$ \\
\hline
\end{tabular}

Legenda - A: Aprovado; R: Reprovado; NR: Não realizado. 


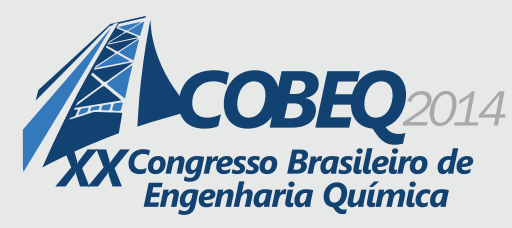

19 a 22 de outubro de 2014

Florianópolis/SC

$\mathrm{Na}$ solução contendo $300 \mathrm{~g} / \mathrm{L}$ de ácido crômico, todas as amostras em PVC puro foram reprovadas no teste de aderência, e em algumas amostras houve falha já na deposição da primeira camada, ou seja, camada de níquel químico. As amostras testadas em temperatura de $70{ }^{\circ} \mathrm{C}$, com tempo de imersão de 15 minutos com concentração de $350 \mathrm{~g} / \mathrm{L}$ e $400 \mathrm{~g} / \mathrm{L}$ foram as únicas amostras aprovadas. Analisando os resultados, observa-se que as concentrações utilizadas de ácido crômico apresentaram resultados positivos a partir de $350 \mathrm{~g} / \mathrm{L}$, valor próximo ao da concentração padrão empregada industrialmente para peças em ABS puro (400 g/L).

Na Figura 2, são apresentadas as imagens de MEV das superfícies das amostras de ABS puro e do PVC puro, antes e após o condicionamento.
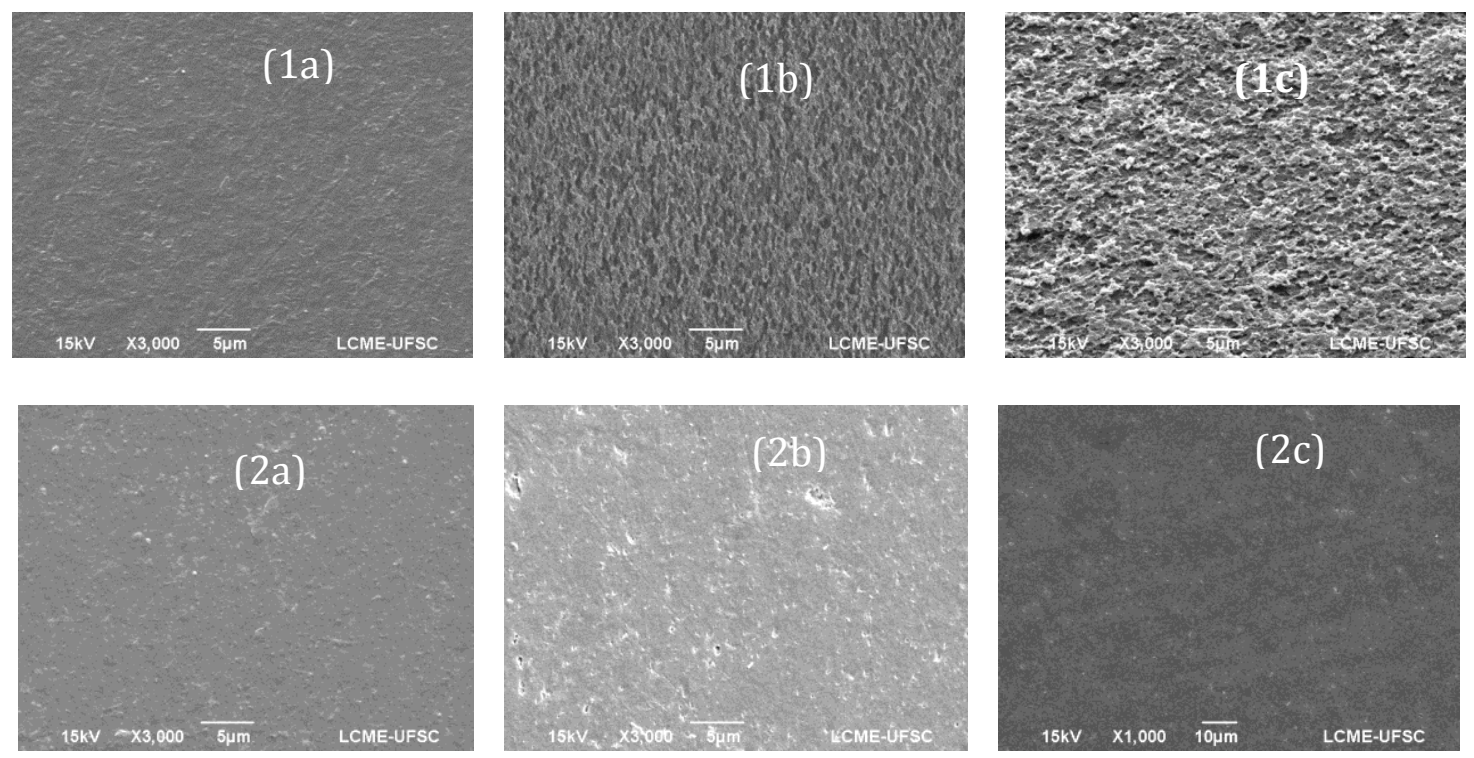

Figura 2: MEV da superfície de ABS puro (1) e PVC puro (2) - (a) sem condicionamento, (b) com tempo de imersão de 5 min e (c) de 15 min, em solução sulfocrômica com concentração de $350 \mathrm{~g} / \mathrm{L}$ de ácido crômico e $400 \mathrm{~g} / \mathrm{L}$ de ácido sulfúrico e a $70{ }^{\circ} \mathrm{C}$.

Comparando as amostras do ABS puro com as amostras de PVC puro, observou-se maior ataque da solução condicionante sulfocrômica para amostra do ABS, porém a amostra de PVC puro quando submetida ao tempo de imersão de 15 minutos, Fig. 2 (2c), mesmo apresentando uma superfície menos rugosa que a do ABS, apresentou resultado positivo no teste de adesão, pois a solução sulfocrômica promoveu alterações na superfície, favorecendo a adesão da camada metálica. Observou-se também a presença de ondulações na superfície das amostras (1b) e (2b), com maior intensidade para a amostra (1c). Estas alterações influenciaram diretamente na deposição metálica e mostraram ser dependentes das condições operacionais (temperatura e tempo) empregadas. Conforme Begun et al (2004), em estudos de metalização de ABS submetido a soluções sulfocrômicas, observaram alterações na rugosidade superficial e adesão satisfatória da camada metálica para amostras submetidas a temperaturas que variaram de 20 a 70 ${ }^{\circ} \mathrm{C}$. Porém, conforme mostrado na Tabela 2, para os testes realizados com ácido crômico, 
verifica-se que sob temperaturas baixas, de $50{ }^{\circ} \mathrm{C}$, as amostras foram reprovadas, nestes casos, provavelmente não ocorreu alteração significativa da morfologia da superfície. Tiganis et al (2002) estudaram a degradação térmica acelerada do ABS sem condicionamento a temperaturas maiores que $80{ }^{\circ} \mathrm{C}$ e observaram que nestas condições ocorre a formação de microporos na superfície da amostra devido à degradação ocasionada. Temperaturas maiores que $70{ }^{\circ} \mathrm{C}$ dificilmente são usadas, pois podem ocasionar deformação das peças durante o tratamento. $\mathrm{O}$ tempo de imersão no condicionamento também é bastante significativo no grau de ataque à superfície, geralmente 5 a 15 minutos, é suficiente para formar um grande número de pequenas cavidades na superfície da peça. Se o tempo for muito prolongado, em alguns casos, a quantidade de poros formados pode ultrapassar a profundidade de 1 a $2 \mu \mathrm{m}$ na superfície da amostra e prejudicar a adesão. E, quando usado em aplicação industrial tempos maiores que 15 minutos podem reduzir a produtividade, tornando inviável o processo.

Os resultados da rugosidade média e amplitude máxima realizada nas amostras de ABS puro e no PVC puro condicionadas em solução sulfocrômica, sob tempos de imersão de 5 e 15 minutos e temperatura $70^{\circ} \mathrm{C}$, estão apresentados na Tabela 3 .

Tabela 3: Rugosidade média e amplitude máxima da superfície de ABS puro e PVC puro antes e após condicionamento em solução sulfocrômica, por 5 e 15 minutos e a $70{ }^{\circ} \mathrm{C}$.

\begin{tabular}{l|l|l|l}
\multicolumn{2}{c}{} & \multicolumn{2}{c}{ Rugosidade } \\
\cline { 3 - 4 } \multicolumn{2}{c}{} & \multicolumn{1}{c}{$\boldsymbol{A B S}$} & \multicolumn{1}{c}{$\boldsymbol{P V C}$} \\
\hline \multirow{2}{*}{$\begin{array}{l}\text { Sem } \\
\text { condicionamento }\end{array}$} & Rugosidade média $(\mathrm{nm})$ & 48,2 & 17,6 \\
\hline \multirow{2}{*}{$\mathbf{5}$ minutos } & Amplitude máxima $(\mathrm{nm})$ & 57,7 & 11,2 \\
\hline \multirow{2}{*}{$\mathbf{1 5}$ minutos } & Rugosidade média $(\mathrm{nm})$ & 230,6 & 28,1 \\
\cline { 2 - 4 } & Amplitude máxima $(\mathrm{nm})$ & 149,0 & 24,1 \\
\hline & Rugosidade média $(\mathrm{nm})$ & 217,0 & 41,8 \\
\cline { 2 - 4 } & Amplitude máxima $(\mathrm{nm})$ & 226,0 & 47,2 \\
\hline
\end{tabular}

$\mathrm{Na}$ Figura 3, são apresentadas as imagens de AFM e gráficos do perfil da rugosidade das superfícies das amostras de ABS puro e do PVC puro, após 15 minutos de tratamento a $70{ }^{\circ} \mathrm{C}$ na solução sulfocrômica contendo 350 g/L de ácido crômico e 400 g/L de ácido sulfúrico. 

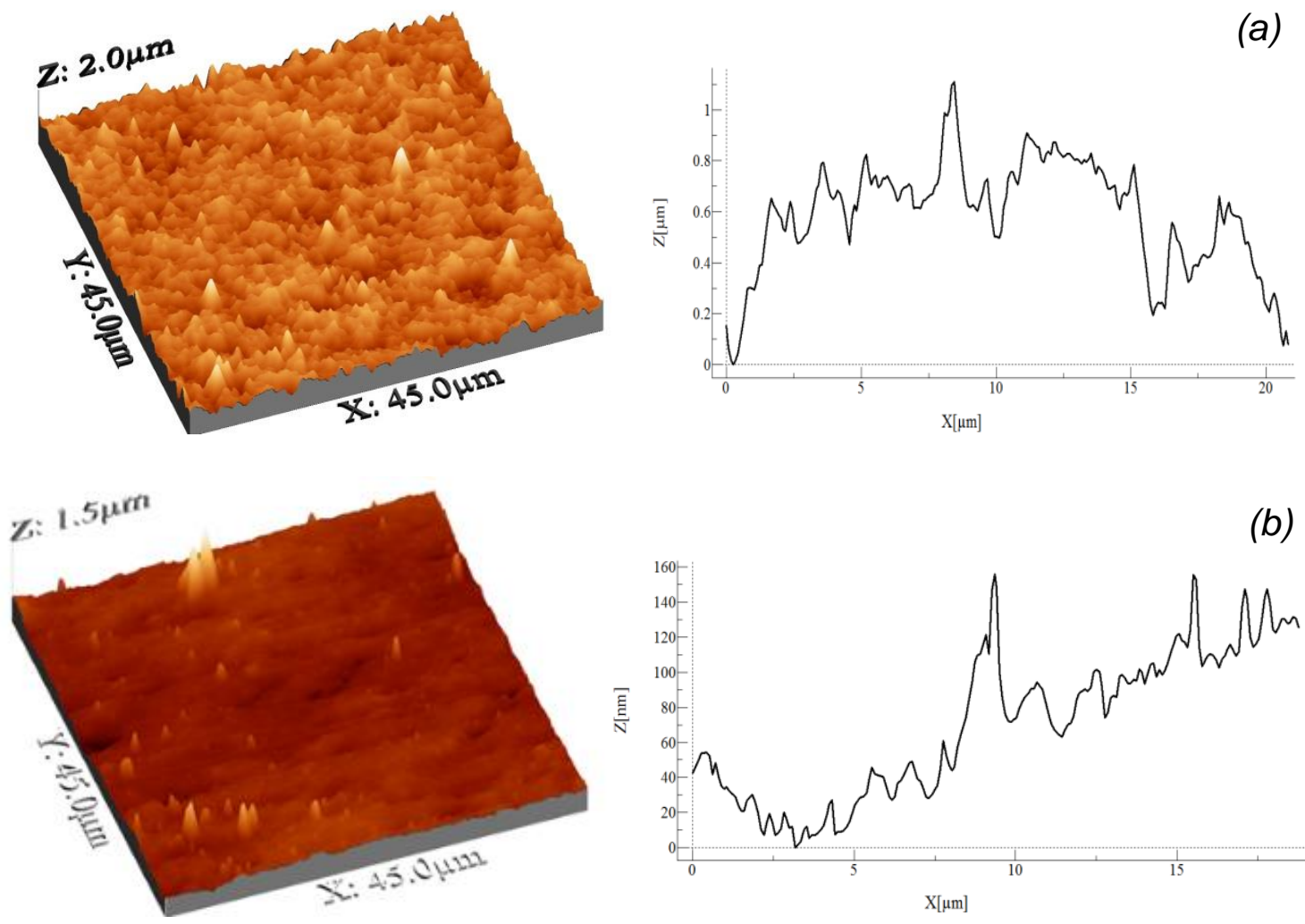

Figura 3: Imagens AFM e gráficos do perfil da rugosidade da superfície de ABS puro (a) e PVC puro (b) com imersão de $15 \mathrm{~min}$, em solução sulfocrômica contendo $350 \mathrm{~g} / \mathrm{L}$ de ácido crômico e $400 \mathrm{~g} / \mathrm{L}$ de ácido sulfúrico e a $70{ }^{\circ} \mathrm{C}$.

Observa-se na imagem de AFM da Fig. 3 (a), que a superfície do ABS condicionada por 15 minutos apresenta picos agudos, com rugosidade média de $217,0 \mathrm{~nm}$, conforme mostrado na Tabela 3. Para a amostra de PVC, Fig. 3 (b), após o ataque, a superfície passa a apresentar estruturas tipo colinas, corroborado pelo aumento da rugosidade média (41,8 nm). $\mathrm{O}$ aumento da rugosidade, ocasionado pelo ataque da solução condicionante de concentração de $350 \mathrm{~g} / \mathrm{L}, 70{ }^{\circ} \mathrm{C}$ e tempo de imersão de 15 minutos, foi suficiente para a adesão da camada metálica. As amostras tratadas com 15 minutos apresentaram superfície com alterações uniformes, ou seja, picos em toda a extensão, indicando que o ataque da superfície foi homogêneo (DOTTO, 2003). Para a modificação de superfícies poliméricas, a escolha do meio de reação e das condições de reação deve ser avaliada após o ataque na superfície do polímero, pois o objetivo não é promover degradação e sim ocasionar alterações na morfologia que favoreçam a adesão das camadas metálicas. 


\section{CONCLUSÃO}

A partir dos ensaios realizados em solução sulfocrômica observou-se resultados positivos de aderência nas peças de PVC puro similares aos já obtidos pelo uso do terpolímero ABS. As alterações ocasionadas com solução sulfocrômica na morfologia da superfície das amostras mostraram ser dependentes da composição do material e das condições operacionais empregadas.

\section{Agradecimentos}

Aos laboratórios LCME/UFSC e LSA-CFM/UFSC pelas análises de MEV e AFM, repectivamente. Às empresas brasileiras Braskem pelo fornecimento do PVC, Durin pelo uso do processo de injeção e Sigmacrom pelos laboratórios e processo de cromagem.

\section{REFERÊNCIAS BIBLIOGRÁFICAS}

Begun Z., GOOSEY T. M., GRAVEZ E. J., POOLE A., SINGH A., Combined adhesion promotion and direct metallization process, USA, United States Patent n.6,790,334 B2, sep. 2004.

BOS A., FELS C., Metalização direta de plásticos ABS e ABS-PC, Revista Tratamento de Superfície, número 172, pág 68 - 71, São Paulo, março-abril/2012.

COURDUVELIS, C I., Composition and Process for treating Plastics with alkaline permanganate solutions, WO 86/00085 - 1986

DAIMLERCHRYSLER - NORMA DBL - 8465; Especificações para Fornecimento de peças de plástico com revestimentos metálicos eletrodepositados - (MERCEDES BENZ DO BRASIL); São Paulo. Outubro /2002;

DOTTO M. E. R.; Universalidade e leis de escalas em amostras de sílicio atacadas quimicamente. Tese de doutorado. UFSC, 2003. $172 \mathrm{f}$

KATO, K., ABS mouldings for electroplating - an electron microscope study, Polymer, 8 ed, p $33-38,1967$.

KUREK, A. P. ; SELLIN, N. ; GELSLEICHTER, M. . Redução e substituição do ácido crômico na etapa de condicionamento de ABS para metalização. Polímeros (São Carlos. Impresso), v. 19, p. 248-254, 2009.

NBR 8094: Material metálico revestido e não-revestido - Corrosão por exposição à névoa salina. Rio de Janeiro, 1983.

NUNES, L.R; RODOLFO, A. Jr.; ORMANJI, W.,Tecnologia do PVC, São Paulo, $2^{\circ}$ ed., Braskem, 2006.

TEIXEIRA, L. A., SANTINI, M. C. Surface conditioning of ABS for metallization without the use of chromium baths, Journal of Materials Processing Technology, número 170 , p 37-41, 2005

TIGANIS B. E., BURN L.S., DAVIS P., HILL A. J., Thermal degradation o acrynolitrilebutadiene-styrene (ABS) blends, Polymer Degradation and Stability, número 76, p. 425-434, 2002. 